\title{
Advances in the tracking of marine species: using GPS locations to evaluate satellite track data and a continuous-time movement model
}

\author{
Carey E. Kuhn*, Devin S. Johnson, Rolf R. Ream, Thomas S. Gelatt \\ National Marine Mammal Laboratory, Alaska Fisheries Science Center/NOAA, 7600 Sand Point Way NE, Seattle, \\ Washington 98115, USA
}

\begin{abstract}
Argos satellite tracking provides information about the large-scale movements of marine species, but the limitations in position accuracy and frequency make it difficult to interpret fine-scale behaviour. With Fastloc global positioning system (GPS) technology, it is now possible to overcome these limitations when tracking diving marine species. We compared differences among archived GPS (GPS), transmitted GPS (GPS-t) and Argos satellite (PTT) tracks acquired simultaneously on 30 northern fur seals Callorhinus ursinus. We examined times and distances between locations, as well as overall trip characteristics (e.g. distance traveled and transit rate). The GPS data were also used to test the accuracy of a continuous-time correlated random walk model created to cope with the spatial error and gap times associated with PTT locations. Significantly more GPS locations per day were acquired than PTT locations (31.6 \pm 1.9 vs. $12.0 \pm 0.3$, respectively), and the GPS locations were more evenly distributed along the track. The influence of data type (GPS, GPS-t, PTT) varied based on the parameter measured, ranging from different among all (e.g. average transit rate) to no significant difference (e.g. maximum distance traveled). Modeling of both PTT and GPS-t data resulted in tracks with over $79 \%$ of predicted locations less than $5 \mathrm{~km}$ from the GPS location (average location error: $3.2 \pm 0.1$ and $1.7 \pm 0.1 \mathrm{~km}$, respectively). This study demonstrates the added benefit of using GPS to track marine species, as well as how and when modeled PTT data may be sufficient to address study questions.
\end{abstract}

KEY WORDS: Movement patterns · At-sea behaviour · GPS tracking $\cdot$ Correlated random walk Resale or republication not permitted without written consent of the publisher

\section{INTRODUCTION}

Argos satellite tracking has been fundamental in increasing our understanding of large-scale movements, space use, and critical habitat of various marine species. However, for many species, information on fine-scale movements is lacking, in part due to the limitations of Argos satellite tracking technology. The first significant limitation is the potential for long periods of time to pass without obtaining a location (over $35 \mathrm{~h}$ in the present study). This can result from tracking species that spend extensive amounts of time underwater (e.g. northern elephant seals Mirounga angustirostris or leatherback turtles Dermochelys coriacea) or from conducting research on species in areas with minimal
Argos satellite coverage (e.g. equatorial species) (Cracknell \& Hayes 1991). Second, once a location is obtained, the potentially large error associated with it (up to $48 \mathrm{~km}$ or more) (Le Boeuf et al. 2000) may swamp the detection of fine-scale movements. Given these limitations, unrealistic movement patterns can be reported when tracking with Argos satellite technology, especially when using simple linear interpolation between locations (Tremblay et al. 2006, Bradshaw et al. 2007).

To compensate for the weakness of Argos satellite tracking, correlated random walk models have been employed to reconstruct tracks that are based on more natural animal movements and to produce predicted locations more consistently distributed in time (Jonsen 
et al. 2007, Johnson et al. 2008). This process is based on the premise that an animal's location is dependent on previous locations and that inertia will keep an animal moving at a similar rate and direction. However, few studies have validated the modeled tracks produced against real data from free-ranging marine species (Schofield et al. 2007, Shillinger et al. 2008, Lea et al. 2009). Without the proper validation, it is unknown if this modeling technique is suitable for accurately describing movement patterns and space use for marine species.

To examine fine-scale movements, a more accurate tracking method that can provide more frequent loca-

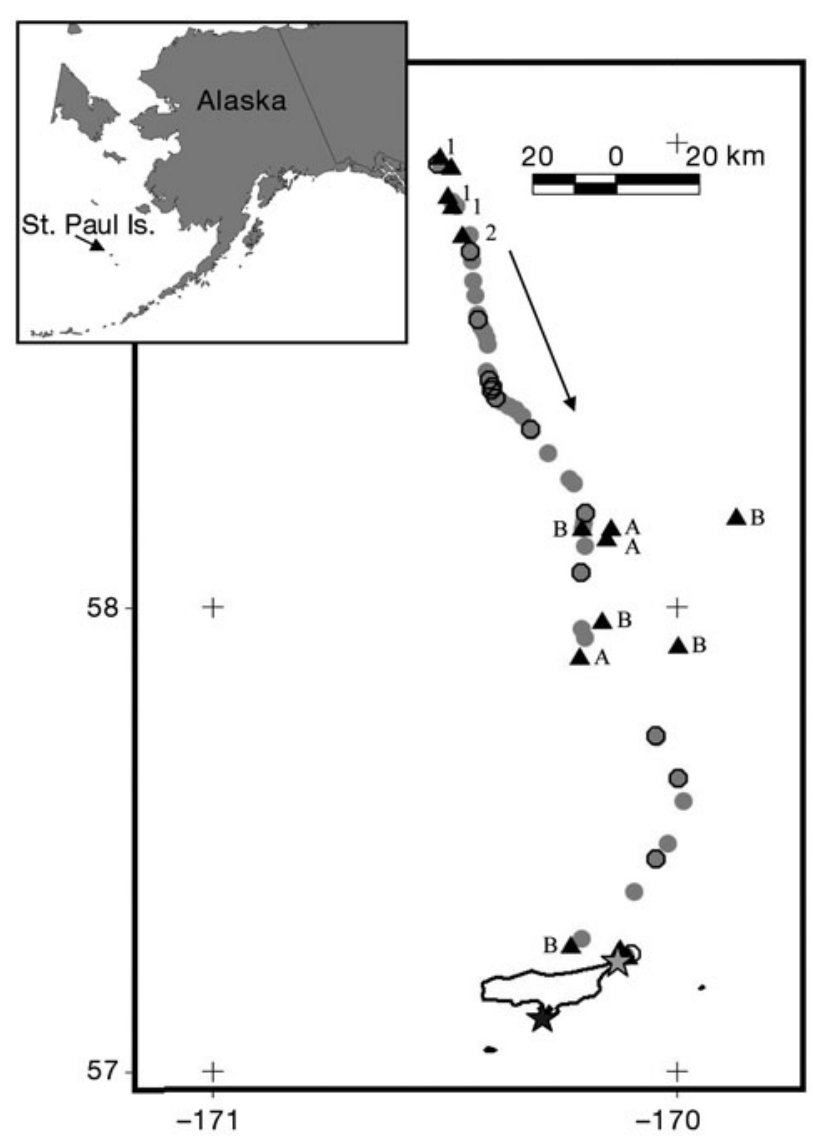

Fig. 1. Callorhinus ursinus. The last $36 \mathrm{~h}$ of a representative foraging trip as a female northern fur seal returned to St. Paul Island, Alaska (arrow shows direction of travel). ( $\mathbf{\Delta})$ filtered PTT locations with location quality listed next to each symbol, (•) filtered GPS locations, and (o) GPS locations that were transmitted via the Argos satellite system (GPS-t). Note PTT locations occur in clusters at the beginning, middle, and end of this section of track while both the GPS and GPS-t locations are distributed more evenly. This clustering of PTT data could be a result of the discontinuous coverage of Argos satellites as PTTs were programmed to transmit continuously when dry. Initial tagging locations at $(\star)$ Reef rookery ( rookery. Inset: St. Paul Island (Alaska), part of the Pribilof Islands located in the Bering Sea tions is necessary. In the terrestrial environment, tracking based on the global positioning system (GPS) has been used extensively (Rempel et al. 1995, Schwartz \& Arthur 1999, Hulbert \& French 2001). Recently, this technology has also been utilized in studies of seabirds (Ryan et al. 2004, Awkerman et al. 2005, Garthe et al. 2007). However, for animals that spend much of their time underwater, traditional GPS instruments are inadequate for obtaining at-sea locations (Ryan et al. 2004, Schofield et al. 2007).

With the development of Fastloc GPS technology (Wildtrack Telemetry Systems) (Bryant 2007), it is now possible to obtain the more accurate, consistent locations previously available for animals in the terrestrial environment (Ryan et al. 2004, Bryant 2007, Hays 2008). Instruments equipped with Fastloc GPS are able to obtain satellite signals in milliseconds and typically can determine locations with an accuracy of less than $50 \mathrm{~m}$ (Bryant 2007). On current tracking instruments the locations can be stored on-board (archived) and/or transmitted through the Argos satellite system (transmitted). Therefore, the objectives of this study were 2fold: (1) to quantify the differences between simultaneously acquired archived GPS (GPS), transmitted GPS (GPS-t), and Argos satellite (PTT) tracks from northern fur seals Callorhinus ursinus and to test the impact of data type on the measurement of movement parameters; and (2) to use archived GPS track data to test the effectiveness of modeling both PTT and GPS-t data using a continuous-time correlated random walk model to account for periods without acquired locations and/or location error. Quantifying the differences between these tracking technologies will better equip scientists to determine which method is most appropriate to accomplish their research objectives.

\section{MATERIALS AND METHODS}

Animal handling. Research was conducted from September to October 2007 and August to October 2008 at St. Paul Island, Alaska $\left(57.2^{\circ} \mathrm{N}, 170.3^{\circ} \mathrm{W}\right)$. Forty-two adult female northern fur seals were instrumented at 2 rookeries, Reef $(\mathrm{n}=20)$ and Vostochni ( $\mathrm{n}$ = 22) (Fig. 1). Females observed nursing or calling for a pup were captured using custom-made hoop nets (Fuhrman Diversified). They were either restrained for instrument attachment or sedated using gas anesthesia (Isoflurane) administered with oxygen. Seals were recaptured 6 to 52 d later, physically restrained for instrument removal, and weighed again prior to release.

Instrumentation. Each animal was equipped with an Mk10-AF tag (Wildlife Computers), which has an Argos transmitter with Fastloc GPS and time-depth 
recorder capabilities. A total of $20 \mathrm{Mk} 10-\mathrm{AF}$ tags were used throughout the 2 years with some instruments being redeployed both within one year and during the following year. Each instrument was programmed to continually send single Argos satellite transmissions every 42 to $47 \mathrm{~s}$ when the saltwater switch was dry ( $24 \mathrm{~h}$ on). After the switch had been dry for 20 min the transmissions were reduced to one every 87 to $92 \mathrm{~s}$, and after $3 \mathrm{~h}$ the instrument stopped transmitting until submerged. The Mk10-AF tag used Fastloc technology to collect and archive a GPS location at 15 min intervals when the animal was above the surface. Along with acquiring an Argos satellite position, the instrument was programmed to transmit the GPS data via the Argos system at the highest priority level. Finally, the Mk10-AF tag sampled dive depth at $5 \mathrm{~s}$ intervals. These data were combined with GPS and satellite locations to determine the precise time animals departed and returned to the rookery. To facilitate instrument recovery, each female was also equipped with a VHF tag (Advanced Telemetry Systems). Instruments were glued directly to the dorsal pelage with quick set epoxy (Devcon 5 Minute).

Data processing and analysis. Three data sets were acquired for each deployment: GPS, GPS-t and PTT. All class Z locations were removed from PTT datasets prior to filtering. To remove erroneous locations, datasets were also filtered based on a maximum transit rate of $2 \mathrm{~m} \mathrm{~s}^{-1}$ using the algorithm described in Freitas et al. (2008). Since all other location qualities $(3,2,1,0, A, B)$ were retained for filtering, the transit rate of $2 \mathrm{~m} \mathrm{~s}^{-1}$ was chosen as it is equal to or more stringent than previous studies tracking fur seals or sea lions $\left(3 \mathrm{~m} \mathrm{~s}^{-1}\right.$, Bailleul et al. 2005, Ream et al. 2005, Lea et al. 2008, Melin et al. $2008 ; 2.8 \mathrm{~m} \mathrm{~s}^{-1}$, Villegas-Amtmann et al. 2008; $2 \mathrm{~m} \mathrm{~s}^{-1}$, Page et al. 2006). This strict filtering requirement was selected in order to retain the highest number of positions yet ensure positions with large error were removed. Trip duration was defined as the period between the time a female left the rookery and the time she returned (based on dive and location data). Trip durations were compared between years using a linear mixed model with year as the fixed factor and 2 random factors: animal ID and individual trips within each female. Locations per day at sea were calculated for each foraging trip from the filtered data. Mean and maximum time between locations (gap times) and distance between locations (gap distances) were calculated for each trip in each filtered data set.

Maximum distance traveled from the rookery was calculated for each foraging trip using the great circle distance from the rookery to the farthest location. The sum of distances between each location was used to calculate total distance traveled and average distance per day at sea. Two metrics for transit rate were used to compare fine-scale and large-scale movements. First, average transit rate was calculated from each filtered location. Since location error in the PTT positions results in a speed value consisting of both real animal movement and location error, daily transit rate was also calculated. Daily transit rate was determined using the highest quality location per day (PTT) or closest location to mid-day (GPS, GPS-t) for the duration of the foraging trip.

Modeling satellite location data. The continuoustime correlated random walk model described by Johnson et al. (2008) was used to predict locations along the foraging track using the filtered PTT data (modeled PTT). In addition to providing predicted locations, the model produces an error estimate for each location based on error estimates for each Argos class and the time between locations (for more details see Johnson et al. 2008). The PTT locations were modeled at hourly intervals to determine differences in maximum distance traveled from the rookery, total distance traveled per trip, total distance traveled per day, average transit rate, and daily transit rate. Additionally, PTT data were modeled at times corresponding to GPS locations to investigate the accuracy of the specific predicted locations when compared to GPS locations. The archived GPS was used as the standard based on the high accuracy demonstrated by manufacturer tests. Bryant (2007) showed that $50 \%$ of locations were within a radius of between 8 and $50 \mathrm{~m}$ (depending on the number of satellites acquired), while $95 \%$ of all locations fell within $630 \mathrm{~m}$. In addition, a simple linear interpolation was used with the filtered PTT data to determine whether modeling improved the accuracy of locations along the track.

Finally, the continuous-time correlated random walk model was used with the GPS-t data to produce a track with predictions at the specific times GPS locations were available. These data were then compared to the track produced by archived GPS data as described below in 'Statistical analysis'. This was to determine if modeling the GPS-t dataset resulted in more accurate locations than modeled PTT data.

Statistical analysis. Location and track characteristics were compared using a linear mixed model. Random factors for the models included animal ID, trips within each animal, and instrument number. Additionally, year was included as a fixed factor (Table 1). The most appropriate model was chosen based on the lowest Bayesian information criterion (BIC) (Burnham \& Anderson 2002). Modeled track locations (PTT, GPS-t) were compared to GPS locations in 2 ways. First, the distance between each archived GPS and modeled track location was determined for each foraging trip to produce frequency distributions of location error and to calculate mean and maximum error $(\mathrm{km})$. Second, 
Table 1. Comparisons between location and track metrics. Tests were conducted using the LME4 package in R 2.8.1. Comparisons are between GPS data and PTT, GPS-t, and modeled PTT data (type). The best model was chosen based on the lowest Bayesian information criterion. ID: unique value for each tracked animal; TripID: foraging trip (range: 1 to 6 per female); Tag_num: unique identifier for the instrument used to track each female

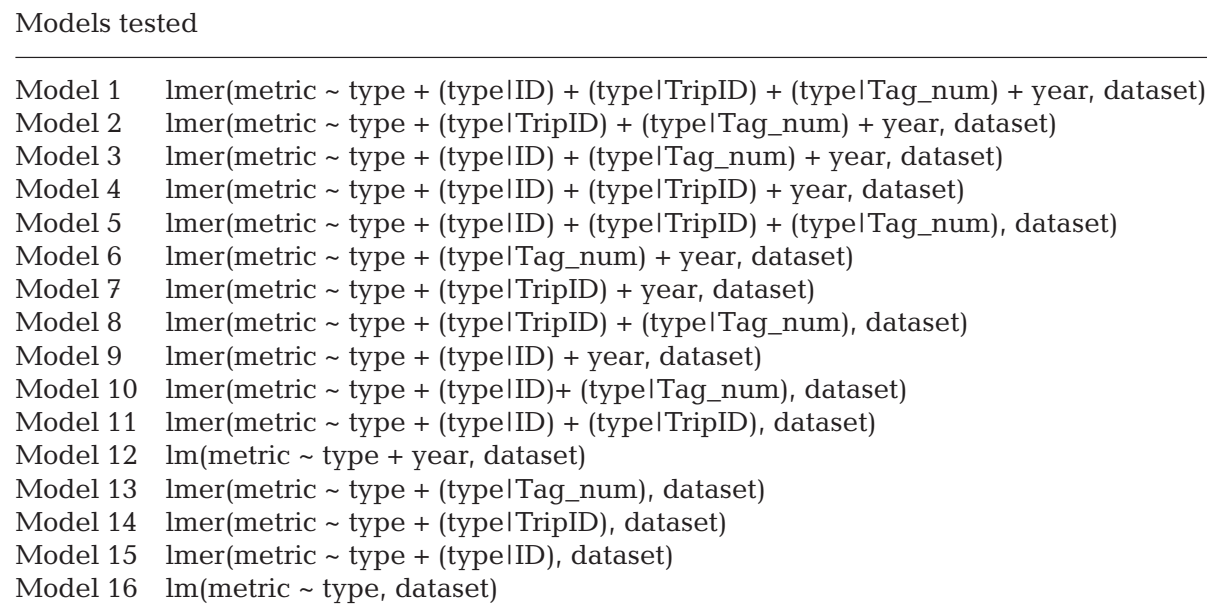

the proportion of GPS locations within the $95 \%$ confidence ellipse of the associated model locations was determined for each track. The average and maximum distance of the longest side of the $95 \%$ confidence ellipses along the track were determined for comparison. Summary data are reported as mean \pm SE. Statistical analysis was conducted using SYSTAT 10 (SPSS Science 2000) and R (R Foundation; http://www.rproject.org). Ranges presented are the minimum and maximum of the average for each foraging trip. Nonnormal data were $\log _{10}$ transformed to improve normality. All contrasts were considered significantly different at $\mathrm{p}<0.05$.

\section{RESULTS}

A total of 70 complete trips with matching PTT, GPS, and GPS-t data were acquired from 30 individuals. At instrumentation, mean fur seal mass was $39.3 \pm 0.6 \mathrm{~kg}$, and females gained an average of $1.4 \pm 0.6 \mathrm{~kg}$ over the tracking period $(21.5 \pm 2.7 \mathrm{~d})$. Trip durations differed between years with an average of $7.0 \pm 0.4 \mathrm{~d}$ in 2007 and $9.0 \pm 0.4 \mathrm{~d}$ in 2008 (difference estimate: $-40.32, \mathrm{SE}=11.72, z=-3.44$ ). There was a significant effect of both animal ID and trip number for trip duration, indicating substantial variation in trip durations among individuals, as well as among different trips for an individual. One female (NFSF2408) was removed from the trip duration and maximum distance data summary as an outlier: she made 2 trips greater than $19 \mathrm{~d}$, and because she was not seen with a pup at recapture, it was presumed she lost her pup. However, this female was included in subsequent analyses, as we were interested in determining how tracking methods compared, and whether she had a pup would not affect these comparisons.

\section{Dataset comparison}

A total of 17172 GPS locations were acquired, which was $2.3 \times$ more than PTT locations. On average, only $37.0 \%(8.2$ to $80.3 \%)$ of the GPS locations were trans-
Table 2. Total locations acquired per trip (unfiltered and filtered) and locations per day (filtered) for GPS, GPS-t, and PTT (mean \pm SE and range provided). Percentage removed was also determined for filtered PTT locations based on each location class $(3,2,1,0, \mathrm{~A}$, and B, Argos 2006). Fewer than $10 \%$ of the PTT locations were removed by filtering for class 3, 2, and 1 quality locations $(3.2,4.6$, and 6.5, respectively). For class $0, \mathrm{~A}$, and B locations just over $20 \%$ were removed from each class by filtering $(21.9,21.9$, and 23.3, respectively). All class $\mathrm{Z}$ locations were removed prior to filtering $(\mathrm{n}=42$, Argos 2006)

\begin{tabular}{|ccccc|}
\hline \multirow{6}{*}{ GPS } & $\begin{array}{c}\text { Locations per trip } \\
\text { (unfiltered) }\end{array}$ & $\begin{array}{c}\text { Locations per trip } \\
\text { (filtered) }\end{array}$ & $\begin{array}{c}\text { Percentage } \\
\text { removed }\end{array}$ & $\begin{array}{c}\text { Locations per day } \\
\text { (filtered) }\end{array}$ \\
\hline GPS-t & $245.3 \pm 21.0$ & $240.8 \pm 20.9$ & $2.2 \pm 0.2$ & $31.6 \pm 1.9$ \\
& $(75-1066)$ & $(72-1059)$ & $(0-8.8)$ & $(8.6-64.7)$ \\
PTT & $(18-0 \pm 6.0$ & $74.8 \pm 5.9$ & $1.8 \pm 0.2$ & $9.6 \pm 0.4$ \\
& $106.9 \pm 5.4$ & $(17-317)$ & $(0-8.6)$ & $(3.1-20.6)$ \\
& $(40-319)$ & $90.3 \pm 4.7$ & $15.5 \pm 0.5$ & $12.0 \pm 0.3$ \\
\end{tabular}




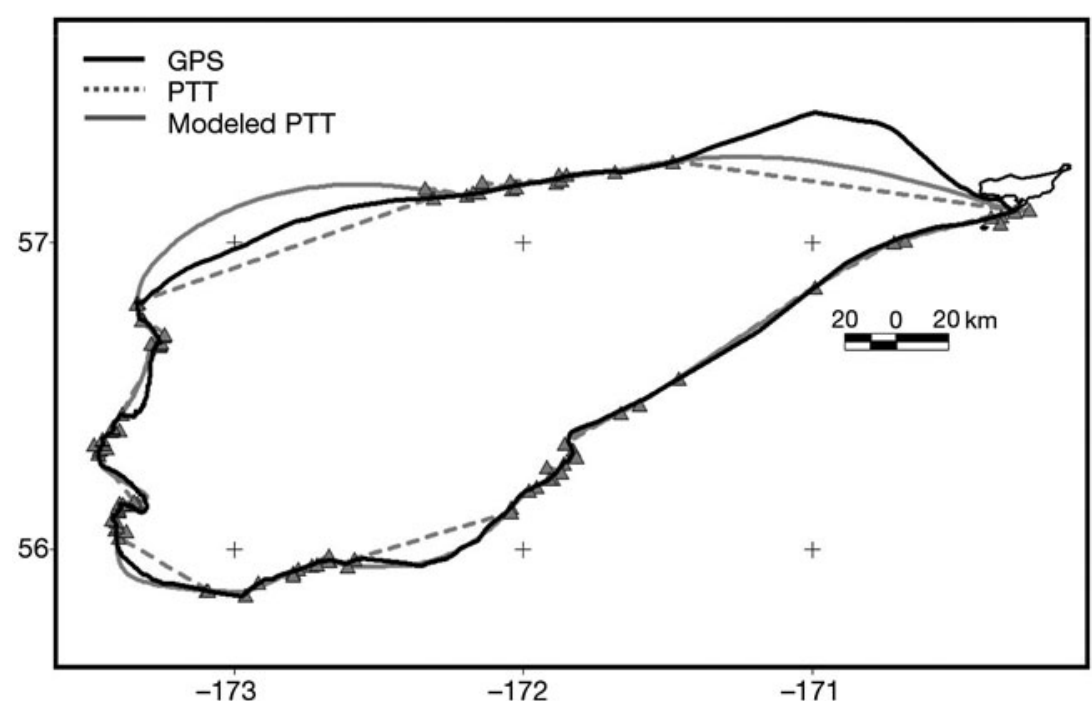

Fig. 2. Callorhinus ursinus. GPS, PTT, and modeled PTT tracks from an adult female northern fur seal tracked from Reef rookery. ( $\Delta$ ) PTT locations. The PTT data were modeled with a continuous-time correlated random walk model at intervals of $1 \mathrm{~h}$. All data points are connected by a linear interpolation. Although females dispersed in different directions and traveled variable distances from the rookery on each foraging trip, this track is representative of the differences found between GPS, PTT, and modeled PTT tracks

mitted (GPS-t), resulting in the lowest number of locations per day from all 3 data sets $(9.6 \pm 0.4)$ (Table 2). Very few GPS locations were removed after filtering $(2.2 \pm 0.02 \%)$, which was similar to the amount removed from the GPS-t data $(1.8 \pm 0.02 \%$ (Table 2$)$. After class Z locations were removed $(\mathrm{n}=42)$, filtering removed an additional $15.5 \pm 0.5 \%$ of the PTT locations ( $\mathrm{n}=1159$ ), with class B locations making up the majority (Table 2).

Not only did GPS provide more locations per day, but these locations were also more consistent in both time and distance along the track (Figs. 1 \& 2, Table 3). Although GPS-t data provided the lowest number of locations per day, when comparisons were made between GPS-t and PTT data for average and maximum gap times and distances, only average gap times were significantly greater for GPS-t data (mean gap time: difference estimate $=-0.09, \mathrm{SE}=$ $0.02, z=-4.7$ ). For all data, mean gap distances were small (range: $3.5 \pm 0.3 \mathrm{~km}$ [GPS] to $9.1 \pm 0.5 \mathrm{~km}$ [GPS-t]) (Table 3 ), but maximum gap distances for both GPS-t and PTT were greater than the average distance a female traveled in a day (Tables $3 \& 4$ ). For all gap metrics except maximum gap distance, there was a detectable effect of instrument number, which is discussed in detail in the next section (Table 5). In addition, for maximum gap distance there was also a detectable effect of animal ID and trip number (Table 5). For both locations per day and average gap distance there was also an effect of trip number (Table 5).

There was distinct variation in the influence of data type on the overall track characteristics measured (Table 4). Only average transit rate calculated between all locations was significantly different for all data sets (GPS-t, PTT, and modeled PTT) in comparison to the GPS data (Tables 4 $\& 5)$. For the remaining trip metrics, differences varied by data type. While PTT data had a significantly higher average transit rate, it was not different when transit rate was calculated based on a single daily location (daily transit rate) (Tables 4 \& 5). In contrast, PTT data were similar for total distance traveled, while both GPS-t and modeled PTT data had significantly lower total travel distances (Tables 4 \& 5). For all trip parameters except daily transit rate, trip number had a detectable effect (Tables 5). For all parameters except total distance traveled per day, year had a detectable effect, with 2008 values being less than 2007 (Table 5). For total distance traveled per day, the animal ID also had a detectable effect (Table 5) signifying individual variation in foraging trips (Call et al. 2008). While there was no difference between datasets for maximum distance traveled, trip number had a detectable effect, and females traveled farther from the rookery in 2007 than 2008 (2007: $329.6 \pm 17.0 \mathrm{~km}$; 2008: $233.2 \pm 18.0 \mathrm{~km}$ ) (Table 5).

Table 3. Distance between locations (gap distance, mean and maximum) and time between locations (gap time, mean and maximum) averaged $( \pm \mathrm{SE})$ for all females. A linear mixed model was used to test for differences between each data set GPS-t, PTT and GPS. For each contrast the $95 \%$ confidence intervals are provided in parentheses for comparison. ${ }^{*}$ Confidence intervals that do not include 0 denote significant differences between values

\begin{tabular}{|lcccc|}
\hline & \multicolumn{2}{c}{$\begin{array}{c}\text { Gap distance }(\mathrm{km}) \\
\text { Mean }\end{array}$} & \multicolumn{2}{c}{ Gap times (h) } \\
& & & Mean & Max \\
\hline GPS & $3.5 \pm 0.3$ & $45.2 \pm 4.5$ & $1.0 \pm 0.07$ & $8.2 \pm 0.7$ \\
GPS-t & $9.1 \pm 0.5$ & $92.4 \pm 5.5$ & $2.7 \pm 0.1$ & $17.4 \pm 0.9$ \\
& $(0.35,0.51)^{*}$ & $(0.29,0.47)^{*}$ & $(0.36,0.54)^{*}$ & $(0.26,0.51)^{*}$ \\
PTT & $8.4 \pm 0.3$ & $84.6 \pm 4.7$ & $2.1 \pm 0.07$ & $17.8 \pm 0.5$ \\
& $(0.33,0.49)^{*}$ & $(0.27,0.42)^{*}$ & $(0.27,0.44)^{*}$ & $(0.31,0.50)^{*}$ \\
& & & & \\
\hline
\end{tabular}




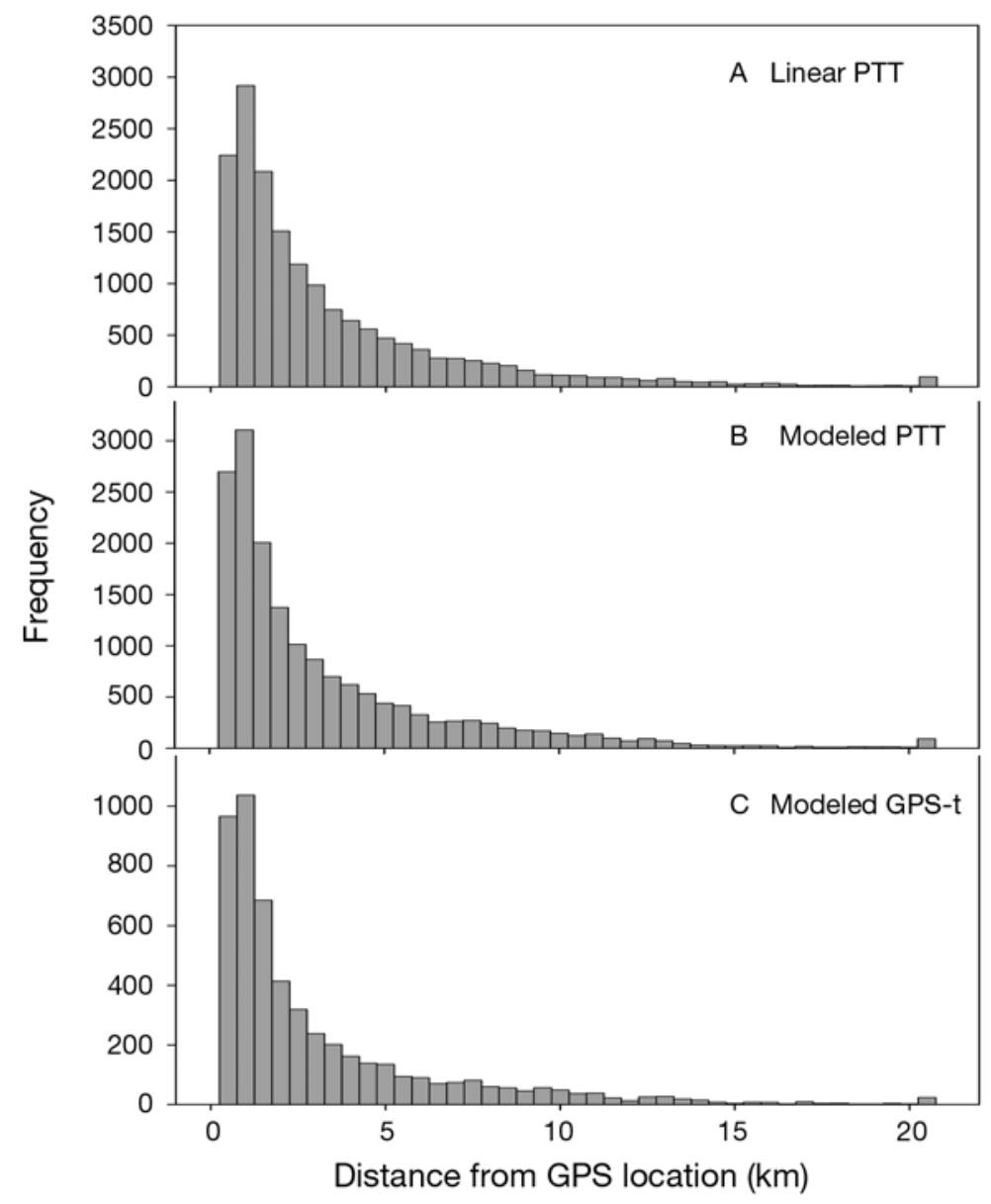

Fig. 3. The distribution of distances $(\mathrm{km})$ calculated between archived GPS data for (A) linearly interpolated PTT, (B) modeled PTT, and (C) modeled GPS-t. Average error distances between linearly interpolated PTT and modeled PTT were not significantly different $\left(F_{1,136}=0.079, \mathrm{p}=0.78\right)$. Average distances between modeled GPS-t locations and archived GPS locations were significantly less than those of modeled PTT data (GPS-t: $3.2 \pm 0.1 \mathrm{~km}$; PTT: $1.7 \pm 0.1 \mathrm{~km}$; difference estimate: $0.37, \mathrm{SE}=0.035, z=$ 10.59). For both distributions less than $1 \%$ of the distances were greater than $17 \mathrm{~km}$

\section{Modeling of track data}

The mean differences between the GPS track locations and both linearly interpolated PTT (linear PTT) locations and the continuous-time correlated random walk model PTT locations (modeled PTT) were not significantly different (linear PTT: $3.3 \pm$ $0.1 \mathrm{~km}$ [range: 1.6 to $6.1 \mathrm{~km}$ ]; modeled PTT: $3.2 \pm 0.1 \mathrm{~km}$ [range: 1.5 to $6.2 \mathrm{~km}$ ], $F_{1,136}=$ 0.079, $\mathrm{p}=0.78$ ) (Fig. 3A,B). In both cases, greater than $79 \%$ of the locations fell within $5 \mathrm{~km}$ or less (linear PTT: 80.0\%; modeled PTT: $79.3 \%$ ), and greater than $50 \%$ fell within $2 \mathrm{~km}$ (linear PTT: 52.5\%; modeled PTT: $54.4 \%$ ). The maximum distance from the GPS track for all females ranged from 6.9 to $81.5 \mathrm{~km}$ (average: $18.1 \pm 1.3 \mathrm{~km}$ ) for linear PTT locations and 6.2 to $82.2 \mathrm{~km}$ (average: $17.9 \pm 1.3 \mathrm{~km}$ ) for modeled PTT locations.

To measure the accuracy of the predicted track produced by the continuous-time correlated random walk model, a 95\% confidence ellipse was created around each modeled PTT location based on the error estimates produced for each location. The proportion of GPS locations within the ellipses averaged $0.76 \pm 0.01$, with a range of 0.57 to 0.95 . However, to put this into perspective it is necessary to know the size of the $95 \%$ confidence ellipses. Overall, the maximum side of the ellipses averaged $7.9 \pm$ $0.4 \mathrm{~km}$ and the average maximum error for all females was $28.5 \pm 1.0 \mathrm{~km}$.

The average difference between modeled GPS-t and GPS locations was significantly different from the modeled PTT values at

Table 4. Callorhinus ursinus. Average transit rate, daily transit rate, total distance traveled per trip, and maximum distance traveled from the rookery for all females and displayed as mean \pm SE (95\% CI) (see 'Materials and methods' for a description of how transit rates were calculated). A linear mixed model was used to test for differences between each data set (GPS-t, PTT, and modeled PTT) and the archived GPS data (GPS). For each contrast the $95 \%$ confidence intervals are provided for comparison. ${ }^{*}$ Confidence intervals that do not include 0 denote significant differences between value

\begin{tabular}{|lccccc|}
\hline & \multicolumn{2}{c}{ Transit rate $\left(\mathrm{km} \mathrm{d}^{-1}\right)$} & & \multicolumn{2}{c|}{ Distance $(\mathrm{km})$} \\
& Average & Daily & Total & Daily & Maximum distance from rookery \\
GPS & $3.3 \pm 0.06$ & $66.5 \pm 1.6$ & $624.3 \pm 26.1$ & $82.3 \pm 1.2$ & $249.8 \pm 11.3$ \\
GPS-t & $3.0 \pm 0.07$ & $66.8 \pm 1.6$ & $582.2 \pm 25.7$ & $76.4 \pm 1.3$ & $251.7 \pm 11.2$ \\
& $(-0.29,-0.13)^{*}$ & $(-0.46,1.14)$ & $(-0.04,-0.03)^{*}$ & $(-0.04,-0.03)^{*}$ & $(-0.01,0.02)$ \\
PTT & $3.8 \pm 0.05$ & $65.8 \pm 1.6$ & $618.6 \pm 26.0$ & $81.7 \pm 1.3$ & $249.3 \pm 11.3$ \\
& $(0.49,0.70)^{*}$ & $(-2.12,0.71)$ & $(-0.01,0.002)$ & $(-0.010,0.004)$ & $(-0.003,0.0001)$ \\
Modeled PTT & $3.0 \pm 0.06$ & $66.7 \pm 1.6$ & $602.1 \pm 25.7$ & $82.8 \pm 2.3$ & $249.9 \pm 11.2$ \\
& $(-0.35,-0.20)^{*}$ & $(-0.52,0.97)$ & $(-0.02,-0.01)^{*}$ & $(-0.02,0.05)$ & $(-0.003,0.005)$ \\
\hline
\end{tabular}


$1.7 \pm 0.1 \mathrm{~km}$ (range: 0.2 to $5.7 \mathrm{~km}$; difference estimate: $0.37, \mathrm{SE}=0.035, z=10.59$ ). Similar to linear and modeled PTT data, $81.5 \%$ of modeled GPS-t tracks fell within $5.0 \mathrm{~km}$ of the GPS, and $58.5 \%$ fell within $2.0 \mathrm{~km}$ of the GPS locations (Fig. 3C). The averages for the maximum distance from the GPS track for all females ranged from 2.2 to $53.1 \mathrm{~km}$ (average: $15.2 \pm 1.1 \mathrm{~km}$ ) and were also significantly lower than the modeled PTT location (difference estimate: 0.094, SE $=0.036, z$ $=2.64$ ). In addition, the total proportion of locations

Table 5. Comparisons between location and track metrics (for models and abbreviations see Table 1). Comparisons were made between GPS data and PTT, GPS-t, and modeled PTT data. The best model was chosen based on the lowest Bayesian information criterion (BIC). For each selected model both the fixed and random effects results are presented

\begin{tabular}{|c|c|c|c|c|c|c|c|c|}
\hline & \multirow[t]{2}{*}{$\mathrm{BIC}$} & \multicolumn{3}{|c|}{ Fixed effect } & \multicolumn{2}{|c|}{ Random effect } & \multicolumn{2}{|c|}{ Random effect } \\
\hline & & Estimate & $\mathrm{SE}$ & $z$ & Variance & $\mathrm{SD}$ & Variance & SD \\
\hline Locations per day (log): model 8 & -275.12 & & & & \multicolumn{2}{|c|}{ TripID } & \multicolumn{2}{|c|}{ Tag_num } \\
\hline GPS & & 1.41 & 0.052 & 27.33 & 0.0031 & 0.056 & 0.051 & 0.22 \\
\hline GPS-t & & -0.47 & 0.045 & -10.48 & 0.011 & 0.10 & 0.034 & 0.18 \\
\hline PTT & & -0.36 & 0.040 & -8.91 & 0.00026 & 0.016 & 0.029 & 0.17 \\
\hline Gap time (log): model 13 & -271.41 & \multicolumn{7}{|c|}{ Tag_num } \\
\hline GPS & & 1.74 & 0.052 & 33.82 & 0.049 & 0.22 & & \\
\hline GPS-t & & 0.45 & 0.044 & 10.17 & 0.032 & 0.18 & & \\
\hline PTT & & 0.035 & 0.043 & 8.30 & 0.030 & 0.17 & & \\
\hline Maximum gap time (log): model 13 & 139.423 & \multicolumn{7}{|c|}{ Tag_num } \\
\hline GPS & & 2.62 & 0.049 & 53.43 & 0.040 & 0.20 & & \\
\hline GPS-t & & 0.38 & 0.063 & 6.12 & 0.064 & 0.25 & & \\
\hline PTT & & 0.40 & 0.050 & 8.13 & 0.037 & 0.19 & & \\
\hline Gap distance (log): model 8 & -240.97 & & & & \multicolumn{2}{|c|}{ TripID } & \multicolumn{2}{|c|}{ Tag_num } \\
\hline GPS & & 0.51 & 0.057 & 8.95 & 0.0053 & 0.073 & 0.0060 & 0.25 \\
\hline GPS-t & & 0.43 & 0.041 & 10.53 & 0.0077 & 0.088 & 0.028 & 0.17 \\
\hline PTT & & 0.41 & 0.041 & 10.15 & 0.000084 & 0.0091 & 0.030 & 0.17 \\
\hline Maximum gap distance (log): model 11 & -55.11 & & & & \multicolumn{2}{|c|}{ TripID } & \multicolumn{2}{|l|}{ ID } \\
\hline GPS & & 1.56 & 0.052 & 30.20 & 0.024 & 0.15 & 0.061 & 0.25 \\
\hline GPS-t & & 0.38 & 0.047 & 8.14 & 0.011 & 0.10 & 0.049 & 0.22 \\
\hline PTT & & 0.34 & 0.038 & 9.13 & 0.0055 & 0.074 & 0.030 & 0.17 \\
\hline Average transit rate: model 7 & 285.47 & \multicolumn{7}{|c|}{ TripID } \\
\hline GPS & & 3.60 & 0.10 & 34.74 & 0.20 & 0.44 & & \\
\hline GPS-t & & -0.21 & 0.041 & -5.07 & 0.044 & 0.21 & & \\
\hline Modeled PTT & & -0.28 & 0.040 & -6.87 & 0.041 & 0.20 & & \\
\hline PTT & & 0.59 & 0.052 & 11.37 & 0.12 & 0.35 & & \\
\hline Year 2008 & & -0.43 & 0.11 & -4.11 & & & & \\
\hline Total distance traveled (log): model 7 & -970.36 & \multicolumn{7}{|c|}{ TripID } \\
\hline GPS & & 2.86 & 0.036 & 79.42 & 0.019 & 0.14 & & \\
\hline GPS-t & & -0.033 & 0.0030 & -11.14 & 0.00014 & 0.12 & & \\
\hline Modeled PTT & & -0.017 & 0.0033 & -5.27 & 0.00026 & 0.016 & & \\
\hline PTT & & -0.0040 & 0.0032 & -1.27 & 0.00021 & 0.015 & & \\
\hline Year 2008 & & -0.11 & 0.039 & -2.87 & & & & \\
\hline Total distance per day: model 11 & -965.44 & & & & \multicolumn{2}{|c|}{ TripID } & \multicolumn{2}{|l|}{ ID } \\
\hline GPS & & 1.91 & 0.087 & 220.78 & 0.0019 & 0.044 & 0.0011 & 0.033 \\
\hline GPS-t & & -0.032 & 0.0036 & -8.91 & 0.000072 & 0.0085 & 0.00014 & 0.012 \\
\hline Modeled PTT & & 0.015 & 0.017 & 0.88 & 0.00014 & 0.012 & 0.0082 & 0.091 \\
\hline PTT & & -0.0029 & 0.0035 & -0.82 & 0.00020 & 0.014 & 0.000089 & 0.0094 \\
\hline Max distance traveled (log): model 7 & -1099.83 & \multicolumn{7}{|c|}{ TripID } \\
\hline GPS & & 2.51 & 0.041 & 61.75 & 0.023 & 0.15 & & \\
\hline GPS-t & & 0.0037 & 0.0068 & 0.54 & 0.0032 & 0.056 & & \\
\hline Modeled PTT & & 0.00089 & 0.0021 & 0.42 & 0.00029 & 0.017 & & \\
\hline PTT & & -0.0012 & 0.00069 & $9-1.79$ & 0.0000079 & 0.0028 & & \\
\hline Year 2008 & & -0.171 & 0.044 & -3.85 & & & & \\
\hline Daily transit rate: model 7 & 1789.31 & \multicolumn{7}{|c|}{ TripID } \\
\hline GPS & & 76.03 & 3.41 & 22.32 & 152.85 & 12.36 & & \\
\hline GPS-t & & 0.34 & 0.41 & 0.83 & 5.60 & 2.37 & & \\
\hline Modeled PTT & & 0.23 & 0.38 & 0.60 & 3.98 & 2.00 & & \\
\hline PTT & & -0.71 & 0.72 & -0.98 & 30.63 & 5.53 & & \\
\hline Year 2008 & & -11.70 & 3.76 & -3.11 & & & & \\
\hline
\end{tabular}




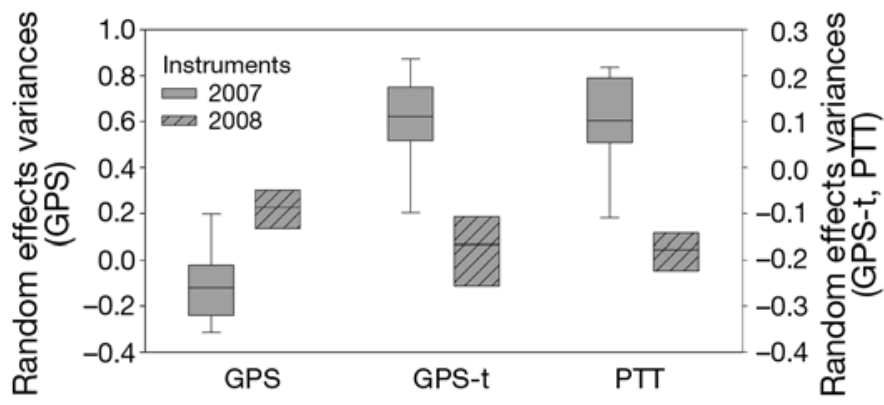

Fig. 4. Random effects variances from the linear mixed model examining differences in number of locations acquired per day based on data type (GPS, GPS-t, PTT). Note the inverse relationship found between the number of acquired locations by year instruments were purchased, for GPS compared to GPS-t and PTT. This trend was also found for average gap times and distances. Although the addition of manufacture year did not improve the model Bayesian information criterion values, it appears there is extensive variability in instrument performance based on when it was manufactured

within the $95 \%$ confidence ellipses was significantly higher at $0.84 \pm 0.1$, with a range of 0.49 to $0.99\left(F_{1,137}\right.$ $=33.65, \mathrm{p}<0.001)$. Further, the $95 \%$ confidence ellipses were significantly smaller on average at $5.3 \pm$ $0.6 \mathrm{~km}$ (difference estimate: $0.30, \mathrm{SE}=0.04, z=7.35$ ). However, the average maximum values for all females were not significantly different $(29.8 \pm 2.2 \mathrm{~km}$; difference estimate: 0.031, $\mathrm{SE}=0.030, z=1.03$ ).

Since tag number had a detectable effect on many of the parameters tested, we were interested to see if there was a pattern in the effect. The random effects variances were examined to determine if a relationship existed between the instrument effect and other potential variables that may influence performance, which included the number of times the instrument was deployed, the total length of all deployments, and the purchase date (2007 or 2008). All instruments except 3 were deployed twice, and no pattern was found between the number of deployments and the random effects variances. In addition, there was no relationship between number of days at sea (transmitting period) and the instrument effect. There was a relationship between purchase date and the random effects variance for locations per day, average gap time, and average gap distance (Fig. 4). Because tags were purchased in 2 batches, the original mixed model was also tested with an additional random factor, manufacture year (2007 and 2008). This did not improve the model's performance and resulted in higher BIC values. Therefore, it appears that although there is a trend of variability in the different instruments purchased each year this is not a distinct 'batch effect' overall. Interestingly, for the tag number effect the 3 data sets responded differently (Fig. 4). There was a trend for more GPS locations per day for the instruments purchased in 2008 but fewer PTT and GPS-t locations per day. As expected, number of locations per day influenced gap metrics, and the average gap times and distances were lower for the GPS data in 2008 but higher for the PTT and GPS-t data.

\section{DISCUSSION}

Although the understanding of at-sea movements of marine predators is critical for management and conservation, the necessity to measure fine-scale behaviour generally depends on the basic research objectives. Given the increased size, cost, and power consumption of Fastloc GPS tags, it is not a straightforward decision to simply switch from Argos satellite to GPS tracking. The Wildlife Computers Mk10-AF tag used for this study was nearly twice the volume and mass of a similar PTT-only instrument available from Wildlife Computers (Spot 5 tag) (Table 6). To minimize the impacts of instrumentation on animal behaviour, the larger instruments may limit the use on some study species, such as smaller marine mammals, turtles, and diving sea birds (Boyd et al. 1997, Watson \& Granger 1998, Ropert-Coudert et al. 2007). Since the Mk10-AF tag is able to collect and archive other valuable high quality data, such as dive depth, external temperature, and light level, a more accurate price and size comparison would probably be between a PTT-only instrument and the Mk10-AFB tag. The alternative Mk10 tag is similar to the Mk10-AF tag in that it is equipped with an Argos transmitter and Fastloc GPS, but does not have the other data archiving capabilities. However, with even this option being nearly double the price, a switch from PTT-only to GPS instruments could further limit sample size in a field where small sample sizes are prevalent (Table 6) (e.g. $\mathrm{n}<10$; McMahon \& Hays 2006, Tremblay et al. 2006, Godley et al. 2008, Takahashi et al. 2008). Nonetheless, depending on the

Table 6. Comparison of the technical specifications for Wildlife Computers PTT-only (Spot 5) and GPS instruments (Mk10-AF, Mk10-AFB). The Mk10-AF tag was used for this study. The Mk10AFB tag has the same Fastloc GPS capabilities and PTT transmitter as the Mk10-AF tag but does not archive additional data such as dive depth, external temperature, and light level. All prices were current as of March 2008

\begin{tabular}{|lrrcc|}
\hline Tag & $\begin{array}{c}\text { Dimensions } \\
(\mathrm{mm})\end{array}$ & $\begin{array}{c}\text { Weight } \\
(\mathrm{g})\end{array}$ & Battery & $\begin{array}{c}\text { Cost } \\
(\mathrm{US} \$)\end{array}$ \\
\hline Mk10-AF & $102 \times 57 \times 31$ & 225 & $4: \mathrm{AA}$ & 5000 \\
Mk10-AFB & $90 \times 57 \times 31$ & $\sim 185$ & $3: 2 / 3 \mathrm{AA}$ & 3400 \\
Spot 5 & $71 \times 54 \times 24$ & 110 & $2:$ AA + 1/2AA & $1350-1700$ \\
\hline
\end{tabular}


length of tracking, the total expense for receiving daily Argos locations could outweigh the price differences for individual instruments. Finally, with the high power consumption of the Fastloc GPS feature (approximately 4 to $6 \times$ that of a PTT transmission; Wildlife Computers Mk10 manual) researchers must find a way to balance the need for high quality data with the frequency of data acquisition if the objective is to obtain longer tracking periods.

\section{Comparisons of trip characteristics}

Regardless of which tracking method is employed, the present study found that large-scale trip-based parameters often do not vary based on the tracking data type (Table 4). This is in contrast to the findings of Ryan et al. (2004), for which filtered PTT tracks of African penguins Spheniscus demersus were considerably shorter than GPS tracks. Interestingly, in the present study the only significant difference between PTT and GPS data was for average transit rate, which was calculated between each acquired location (Table 4). However, this does not necessarily mean that the 2 data sets are describing similar behaviour. While the GPS data incorporated fine-scale searching in the total distance traveled, the PTT data instead incorporated location error that was not a part of the animals' true movements (Hays et al. 2001). This became more evident when comparing GPS and GPS-t datasets. Since GPS-t provided the fewest locations per day, there was an overall loss of fine-scale movements (Fig. 5, inset), and the total distance traveled for GPS-t data was significantly less. This was also the case for the modeled PTT data, for which tracks were adjusted for location error and the overall result was that the calculated distance traveled was significantly less compared to GPS data.

Another consideration for the transition to GPS tracking is that in order to obtain the highest resolution data the instruments must be recovered. In many cases this is not possible due to the difficulty of relocating

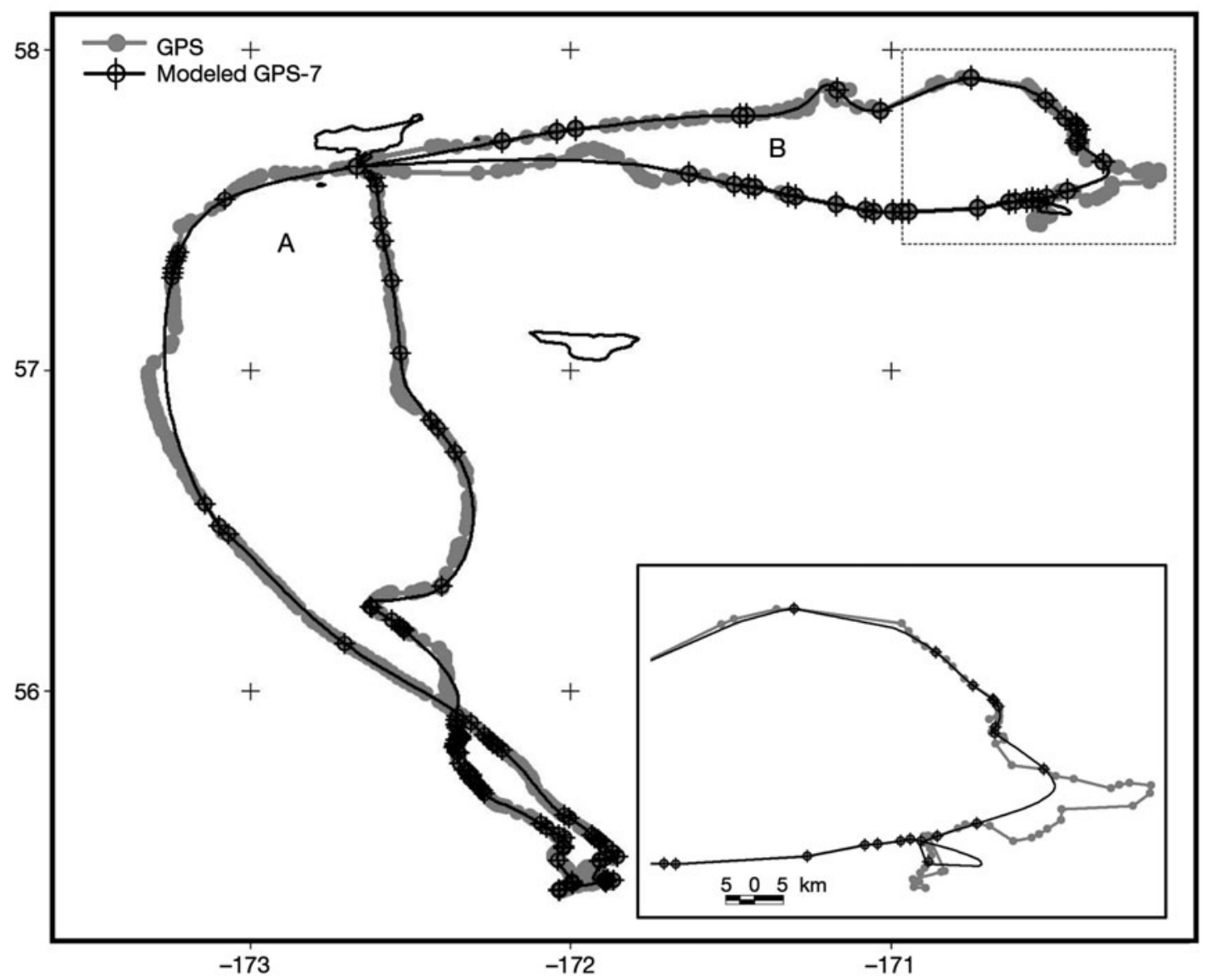

Fig. 5. Callorhinus ursinus. GPS and modeled GPS-t tracks from 2 adult female northern fur seals (A, B). All data points are connected by a linear interpolation. The track of Female A shows a close relationship between the 2 datasets; however some finescale movements are lost for Female B's modeled track. The dashed box denotes the area of Female B's track expanded in the inset where the detailed fine-scale movements obtained by GPS tracking can be observed 
and/or recapturing instrumented animals. While some GPS data can be acquired through transmission to the Argos satellite system, for some instruments as little as $8 \%$ of the GPS locations were transmitted (average $37 \%)$. Therefore, when archived data is not available, the next question is whether modeled PTT or GPS-t data result in tracks that most resemble the animals' actual movement. In the case of GPS-t data, the average periods without locations are larger; but similar to archived GPS, the data were generally distributed more evenly in space and time (Table 3, Fig. 1). The added benefit of the GPS-t data is that researchers will have a significantly higher confidence in the precise locations obtained (Bryant 2007), and depending on the quantity of locations transmitted, even fine-scale movements can be ascertained (Fig. 5, track A).

\section{Comparisons of location accuracy}

In addition to understanding overall foraging trip characteristics, some studies require accurately locating animals at sea in both space and time (e.g. Garthe et al. 2007, Schofield et al. 2007, Weimerskirch et al. 2007). In the present study, the GPS tags were set to sample at 15 min intervals when the animal was at the surface. This resulted in an average of one location per hour, which was significantly higher than what was achieved through Argos satellite tracking (Table 3). Since these instruments allow for a variety of programming options, we suspect much finer temporal resolution can be achieved if required. For example, an average of 51 in-water locations per day were acquired when tracking nesting loggerhead sea turtles Caretta caretta using an increased sampling rate (Schofield et al. 2007). Mattern et al. (2007) were able to receive on average a location every $2.7 \mathrm{~min}$ when tracking yellow-eyed penguins Megadyptes antipodes with GPS instruments, which closely matches the average dive durations measured.

Interestingly, the continuous-time correlated random walk modeling of the filtered PTT data did not reduce the overall error for each predicted location along the track. However, the benefit of this type of modeling is that researchers can have predicted locations evenly spaced in time along the track, and with each location there is an estimate of confidence that incorporates both location accuracy and time between locations (Johnson et al. 2008). As model outcomes are influenced by the raw data inputs, we suspect both the relatively high number of PTT locations acquired per day (discussed in detail in next section), and the high latitude location of the study site resulted in linear PTT tracks with a small degree of overall error. Therefore, modeling did not result in any drastic changes to the track.
Although average differences between spatial accuracy of the modeled PTT and GPS-t locations were small (mean: 3.2 vs. $1.7 \mathrm{~km}$ ), these differences may become biologically significant when precision is critical. For coastal species or ones that make small-scale movements, an increase in measurement error of $50 \%$ could mask important biological signals or space use (Bradshaw et al. 2007). When tracking nesting turtles, Schofield et al. (2007) found females primarily used an area of just over $18 \mathrm{~km}$ of coastline. In addition, by using GPS to accurately identifying sea turtle locations at sea, these researchers found that over $50 \%$ of the time nesting turtles were found outside of the no-boating zone designated for protection and therefore suggested this area needs to be expanded. Finally, due to the accuracy of GPS locations, direct interactions between animals and anthropogenic habitat use or disturbances can also be investigated (e.g. Goldsworthy et al. 2007, Mate 2008, Miller et al. 2009).

\section{Factors influencing PTT data}

Many factors may impact the differences found between GPS and PTT data, but we expect the quantity of PTT data obtained will have a strong influence. In comparison to other recent tracking studies, when considering only continuously transmitting PTTs and either raw PTT data or data that was filtered in a similar manner, our dataset appears to be near the high end of the average number of PTT locations per day received. For example, Tremblay et al. (2006) reported filtered locations per day ranging from 0.9 to 12.0 for 5 pinniped species. Studies of both New Zealand sea lions Phocarctos hookeri and fur seals Arctocephalus fosteri also fell near this range (Chilvers et al. 2005, average filtered locations per day 12.6; Page et al. 2006, average filtered locations per day 2.7-7.9, respectively). Another study of 2 high-latitude pinniped species, the Antarctic fur seal A. gazella and sub-Antarctic fur seal A. tropicalis, obtained a higher number of locations per day compared to both the present study and those previously mentioned ( $>14.0$ locations per day; Bailleul et al. 2005). For penguin species the average locations per day were generally comparable to pinnipeds. For 5 penguin species, filtered and unfiltered locations per day ranged from 3.3 to 18.7 (Lescroël \& Bost 2005, gentoo penguins Pygoscelis papua 10.2 to 18.7 locations d ${ }^{-1}$; Tremblay et al. 2006, macaroni penguin Eudyptes chrysolophus 3.3 to 4.7 locations $\mathrm{d}^{-1}$; Boersma et al. 2007, Magellanic penguins Spheniscus magellanicus 12.0 locations $\mathrm{d}^{-1}$ and Humboldt penguins $S$. humboldti 14.9 locations $\mathrm{d}^{-1}$; Trathan et al. 2008, king penguin Aptenodytes patagonicus $>7$ locations $\mathrm{d}^{-1}$ ). Studies of other marine species 
often obtain even fewer locations per day on average. For example, a study of leatherback turtles Dermochelys coriacea in French Guiana obtained on average well under 10 filtered locations per day (Fossette et al. 2007). Godley et al. (2003) obtained an average of 1.0 and 4.3 unfiltered locations per day when tracking 2 loggerhead turtles Caretta caretta. A similar range of unfiltered locations per day was also acquired in a study tracking green turtles Chelonia mydas (Godley et al. 2002). In both of these cases the unfiltered locations per day are less than $20 \%$ of the filtered locations acquired in this study.

Although many factors can impact the number of locations obtained (e.g. study species surface behaviour or time underwater, study location, instrument type, instrument programming), we suspect both the study animal and study location played a significant role in the large number of PTT locations acquired. Northern fur seals rest and groom at the surface, allowing for extended periods when satellite locations can be obtained (Insley et al. 2008). In addition, as Argos satellite coverage increases towards the poles, the high latitude of our study location likely played a role in the elevated the number of PTT locations $\left(57.1^{\circ} \mathrm{N}\right)$ (Cracknell \& Hayes 1991, Sherman 1992). Therefore, when deciding between tracking methods, consideration must be given to the study site and species. If either is expected to produce fewer PTT locations per day than measured here, we predict the differences between GPS and PTT locations will only increase, especially in relation to gap times and distances. This would suggest that GPS tracking may be most beneficial with species that surface less frequently and/or are in areas with limited Argos satellite coverage (i.e. equatorial regions).

\section{Linking animal behaviour and environmental characteristics}

To understand the fine-scale movements and habitat selection of marine species, many scientists strive to examine how animals respond to their environment. When using the fine-scale movements measured by GPS, there is a mismatch between the scale of the GPS data and remotely sensed oceanographic data (e.g. sea surface temperature [SST], chlorophyll concentration). Not only is this mismatch based on spatial differences, as remotely-sensed data are often collected over a broad area (GPS: $m_{i}$ SST: $\mathrm{km}$ or more), but it is also a result of temporal differences associated with restricted data collection, such as during periods with dense clouds (Bradshaw et al. 2004, Biuw et al. 2007). However, based on our results, the scale of remotely sensed data can be closely related to the accuracy of both modeled PTT and modeled GPS-t data $(3.2 \pm 0.1$ and $1.7 \pm 0.1 \mathrm{~km}$, respectively). Consequently, for large-scale movements these datasets may be adequate when investigating the environmental factors that influence behaviour.

To match both the temporal and spatial scale of the fine-scale behaviour measured by GPS, it is necessary to collect environmental data either from ship-based surveys (e.g. Garthe et al. 2007, Ichii et al. 2007, Pichegru et al. 2007) or from the animal to directly link changes in behaviour with environmental parameters (Boehlert et al. 2001, Biuw et al. 2007, Kitagawa et al. 2007, Takahashi et al. 2008). Studies using instruments that can simultaneously track behaviour and collect environmental data have provided detailed information about how many marine species respond to the thermal structure of their environment, including fronts and thermoclines (McMahon et al. 2007, Takahashi et al. 2008, Trathan et al. 2008). In addition, Biuw et al. (2007) linked successful foraging areas of southern elephant seals with distinct water masses measured by the seals that differed in temperature and salinity. These studies have shown that linking animalacquired environmental data and at-sea movements can improve the understanding of the behaviour of marine species. With the benefit of the highly accurate, more frequent locations provided by GPS, future studies will be able to accurately link fine-scale movement patterns and the factors that influence behaviour to better understand the distribution and critical habitat of marine species.

In addition to characterizing foraging habitat, the fine-scale movement data provided by GPS instruments can be valuable for understanding other aspects of the ecology of marine species, such as foraging decisions, energetics, or demographics. For example, searching and feeding behaviour at multiple spatial scales were examined in albatross by coupling GPS tracks with measures of prey ingestion (Weimerskirch et al. 2007). Pichegru et al. (2007) used similar GPS data from gannets to create a bioenergetics model to help explain differences in population trajectories between 2 colonies. With the recent development of Fastloc GPS technology similar studies with diving marine species can be conducted.

\section{CONCLUSIONS}

Although GPS instruments can provide fine-scale detail $(>100 \mathrm{~m})$ about at-sea movements and animal locations, there are important tradeoffs to consider (e.g. increased instrument size and cost). If large-scale patterns are of interest, both PTT and transmitted GPS data can be modeled to closely approximate animal 
movement patterns. However, for questions requiring an understanding of fine-scale movements or precise animal locations both spatially and temporally, GPS tags are truly the future of biologging technology in the marine realm.

Acknowledgments. This research was conducted under Marine Mammal Protection Act permit number 782-1708-04. We thank J. Baker, K. Call, C. Dorr, B. Fadely, E. Kunisch, K. Sweeney, J. Thomason, R. Towell, and T. Zeppelin for assistance with field research and logistical support. Exceptional veterinary support was provided by D. DeGhetto and F. Nutter. J. London, H. Mostman-Liwanag, and M. Rutishauser offered helpful comments on previous drafts. This research was performed while C.E.K. held a National Research Council Research Associateship Award at the Alaska Fisheries Science Center's National Marine Mammal Laboratory (NOAA). Reference to trade names does not imply endorsement by the National Marine Fisheries Service, NOAA.

\section{LITERATURE CITED}

Argos (2006) Argos user's manual. CLS, Ramonville SaintAgne, available at www.argos-system.org/manual/

> Awkerman JA, Fukuda A, Higuchi H, Anderson DJ (2005) Foraging activity and submesocale habitat use of waved albatrosses Phoebastria irrorata during chick-brooding period. Mar Ecol Prog Ser 291:289-300

Bailleul F, Luque S, Dubroca L, Arnould JPY, Guinet C (2005) Differences in foraging strategy and maternal behaviour between two sympatric fur seal species at the Crozet Islands. Mar Ecol Prog Ser 293:273-282

Boehlert GW, Costa DP, Crocker DE, Green P, O'Brien T, Levitus S, Le Boeuf BJ (2001) Autonomous pinniped environmental samplers: using instrumented animals as oceanographic data collectors. J Atmos Ocean Technol 18: 1882-1893

Biuw M, Boehme L, Guinet C, Hindell M and others (2007) Variations in behavior and condition of a Southern Ocean top predator in relation to in situ oceanographic conditions. Proc Natl Acad Sci USA 104:13705-13710

Boersma PD, Rebstock GA, Stokes DL, Majlui P (2007) Oceans apart: conservation models for two temperate penguin species shaped by the marine environment. Mar Ecol Prog Ser 335:217-225

Boyd IL, McCafferty DJ, Walker TR (1997) Variation in foraging effort by lactating Antarctic fur seals: response to simulated increased foraging costs. Behav Ecol Sociobiol 40: 135-144

Bradshaw CJA, Higgins J, Michael KJ, Wotherspoon SJ, Hindell MA (2004) At-sea distribution of female southern elephant seals relative to variation in ocean surface properties. J Mar Sci 61:1014-1027

Bradshaw CJA, Sims DW, Hays GC (2007) Measurement error causes scale-dependent threshold erosion of biological signals in animal movement data. Ecol Appl 17: 628-638

Bryant E (2007) Fastloc Technical Report TR01: 2D location accuracy statistics for Fastloc ${ }^{\circledR}$ cores running firmware versions $2.2 \& 2.3$, available at www.wildtracker.com/ news.htm

Burnham KP, Anderson DR (2002) Model selection and multimodel inference: practical information-theoretic approach, 2nd edn. Springer, New York
Call KA, Ream RR, Johnson D, Sterling JT, Towell RG (2008) Foraging route tactics and site fidelity of adult female northern fur seals (Callorhinus ursinus) around the Pribilof Islands. Deep Sea Res II 55:1883-1896

Chilvers BL, Wilkinson IS, Duignan PJ, Gemmell NJ (2005) Summer foraging areas for lactating New Zealand sea lions Phocarctos hookeri. Mar Ecol Prog Ser 304:235-247

Cracknell AP, Hayes LWB (1991) Introduction to remote sensing, 2nd edn. Taylor and Francis, London

Fossette S, Ferraroli S, Tanaka H, Ropert-Coudert Y and others (2007) Dispersal and dive patterns in gravid leatherback turtles during the nesting season in French Guiana. Mar Ecol Prog Ser 338:233-247

> Freitas C, Lydersen C, Ims RA, Fedak MA, Kovacs KM (2008) A simple new algorithm to filter marine mammal Argos locations. Mar Mamm Sci 24:315-325

Garthe S, Montevecchi WA, Davoren GK (2007) Flight destinations and foraging behaviour of northern gannets (Sula bassana) preying on small forage fish in a low-Arctic ecosystem. Deep Sea Res II 54:311-320

> Godley BJ, Richardson S, Broderick AC, Coyne MS, Glen F, Hays GC (2002) Long-term satellite telemetry of the movements and habitat utilization by green turtles in the Mediterranean. Ecography 25:352-362

Godley BJ, Broderick AC, Glen F, Hays GC (2003) Post-nesting movements and submergence patterns of loggerhead marine turtles in the Mediterranean assessed by satellite tracking. J Exp Mar Biol Ecol 287:119-134

Godley BJ, Blumenthal JM, Broderick AC, Coyne MS, Godfrey MH, Hawkes LA, Witt MJ (2008) Satellite tracking of sea turtles: Where have we been and where do we go next? Endang Species Res 4:3-22

Goldsworthy SA, Hamer D, Page B (2007) Assessment of the implications of interactions between fur seals and sea lions and the southern rock lobster and gillnet sector of the Southern and Eastern Scalefish and Shark Fishery (SESSF) in South Australia. Final report to the Fisheries Research and Development Corporation. FRDC Project Number 2005/77. SARDI Aquatic Sciences, Adelaide

> Hays GC (2008) Sea turtles: a review of some key recent discoveries and remaining questions. J Exp Mar Biol Ecol $356: 1-7$

> Hays GC, Åkesson S, Godley BJ, Luschi P, Santidrian P (2001) The implications of location accuracy for the interpretation of satellite-tracking data. Anim Behav 61:1035-1040

> Hulbert IA, French J (2001) The accuracy of GPS for wildlife telemetry and habitat mapping. J Appl Ecol 38:869-878

> Ichii T, Bengston JL, Boveng PL, Takao Y and others (2007) Provisioning strategies of Antarctic fur seals and chinstrap penguins produce different responses to distribution of common prey and habitat. Mar Ecol Prog Ser 344:277-297

> Insley SJ, Robson BW, Yack T, Ream RR, Burgess WC (2008) Acoustic determination of activity and flipper stroke rate in foraging northern fur seal females. Endang Species Res $4: 147-155$

Johnson DS, London JM, Lea MA, Durban JW (2008) Continuous-time correlated random walk model for animal telemetry data. Ecology 89:1208-1215

> Jonsen ID, Myers RA, James MC (2007) Identifying leatherback turtle foraging behaviour from satellite telemetry using a switching state-space model. Mar Ecol Prog Ser 337:255-264

> Kitagawa T, Boustany AM, Farwell CJ, Williams TD, Castleton MR, Block BA (2007) Horizontal and vertical movements of juvenile bluefin tuna (Thunnus orientalis) in relation to seasons and oceanographic conditions in the eastern Pacific Ocean. Fish Oceanogr 16:409-421 
Le Boeuf BJ, Crocker DE, Costa DP, Blackwell SB, Webb PM, Houser DS (2000) Foraging ecology of northern elephant seals. Ecol Monogr 70:353-382

Lea MA, Guinet C, Cherel C, Hindell M, Dubroca L, Thalmann S (2008) Colony-based foraging segregation by Antarctic fur seals at the Kerguelen Archipelago. Mar Ecol Prog Ser 358:273-287

Lea MA, Johnson D, Ream R, Sterling J, Melin S, Gelatt T (2009) Extreme weather events influence dispersal of naive northern fur seals. Biol Lett 5:252-257

Lescroël A, Bost CA (2005) Foraging under contrasting oceanographic conditions: the gentoo penguin at Kerguelen Archipelago. Mar Ecol Prog Ser 302:245-261

Mate B (2008) An Argos-GPS-TDR tag monitors precise movements and dive behavior to make prolonged large whale controlled exposure experiments possible. Published Abstracts 3rd International Biologging Science Symposium, 1-5 September 2008. Pacific Grove, p 54, http://biologging.wordpress.com/abstracts/

Mattern T, Ellenberg U, Houston DM, Davis LS (2007) Consistent foraging routes and benthic foraging behaviour of yellow-eyed penguins. Mar Ecol Prog Ser 343:295-306

McMahon CR, Hays GC (2006) Thermal niche, large-scale movements and implications of climate change for a critically endangered marine vertebrate. Glob Change Biol 12: 1330-1338

McMahon CR, Bradshaw CJA, Hays GC (2007) Satellite tracking reveals unusual diving characteristics for a marine reptile, the olive ridley turtle Lepidochelys olivacea. Mar Ecol Prog Ser 329:239-252

Melin SR, DeLong RL, Siniff DB (2008) The effects of El Niño on the foraging behavior of lactating California sea lions (Zalophus californianus) during the nonbreeding season. Can J Zool 86:192-206

Miller PJO, Johnson MP, Madsen PT, Biassoni N, Quero M, Tyack PL (2009) Using at-sea experiments to study the effects of airguns on the foraging behavior of sperm whales in the Gulf of Mexico. Deep Sea Res II 56: $1168-1181$

Page B, McKenzie J, Sumner MD, Coyne M, Goldsworthy SD (2006) Spatial separation of foraging habitats among New Zealand fur seals. Mar Ecol Prog Ser 323:263-279

Pichegru L, Ryan PG, van der Lingen CD, Coetzee J, RopertCoudert Y, Grémillet D (2007) Foraging behaviour and energetics of Cape gannets Morus capensis feeding on live prey and fishery discards in the Benguela upwelling system. Mar Ecol Prog Ser 350:127-136

Editorial responsibility: Hans Heinrich Janssen, Oldendorf/Luhe, Germany
Ream RR, Sterling JT, Loughlin TR (2005) Oceanographic features related to northern fur seal migratory movements. Deep Sea Res II 52:823-843

Rempel RS, Rodgers AR, Abraham KF (1995) Performance of a GPS animal location system. J Wildl Manage 61: $530-539$

> Ropert-Coudert Y, Knott N, Chiaradia A, Kato A (2007) How do different data logger sizes and attachment positions affect the diving behaviour of little penguins? Deep Sea Res II 54:415-423

> Ryan PG, Petersen SL, Peters G, Grémillet D (2004) GPS tracking a marine predator: the effects of precision, resolution, and sampling rate on foraging tracks of African penguins. Mar Biol 145:215-223

Schofield G, Bishop CM, MacLean G, Brown P and others (2007) Novel GPS tracking of sea turtles as a tool for conservation management. J Exp Mar Biol Ecol 347:58-68

Schwartz CC, Arthur SM (1999) Radiotracking large wilderness mammals: integration of GPS and Argos technology. Ursus 11:261-273

Sherman J (1992) Observations of Argos performance. J Atmos Ocean Technol 9:323-328

Shillinger GL, Palacios DM, Bailey H, Bograd SJ and others (2008) Persistent leatherback turtle migrations present opportunities for conservation. PLoS Biol 6:e171

Takahashi A, Matsumoto K, Hunt GL Jr, Shultz MT and others (2008) Thick-billed murres use different diving behaviors in mixed and stratified waters. Deep Sea Res II 55: 1837-1845

- Trathan PN, Bishop C, Maclean G, Brown P, Fleming A, Collins MA (2008) Linear tracks and restricted temperature ranges characterise penguin foraging pathways. Mar Ecol Prog Ser 370:285-294

> Tremblay Y, Shaffer SA, Fowler SL, Kuhn CE and others (2006) Interpolation of animal tracking data in a fluid environment. J Exp Biol 209:128-140

Villegas-Amtmann S, Costa DP, Tremblay Y, Salazar S, Aurioles-Gamboa D (2008) Multiple foraging strategies in a marine apex predator, the Galapagos sea lion Zalophus wollebaeki. Mar Ecol Prog Ser 363:299-309

Watson KP, Granger RA (1998) Hydrodynamic effect of a satellite transmitter on a juvenile green turtle (Chelonia mydas). J Exp Biol 201:2497-2505

Weimerskirch H, Pinaud D, Pawlowski F, Bost CA (2007) Does prey capture induce area-restricted search? A fine-scale study using GPS in a marine predator, the wandering albatross. Am Nat 170:734-743

Submitted: March 10, 2009; Accepted: July 17, 2009

Proofs received from author(s): October 20, 2009 